\title{
Titanium dioxide supported ruthenium nanoparticles for carbon sequestration reaction
}

\author{
Praveenkumar Ramprakash Upadhyay, Vivek Srivastava* \\ NIIT University, NH-8 Jaipur/Delhi Highway, Neemrana (Rajasthan), 301705, India \\ *vivek.shrivastava@niituniversity.in
}

DOI 10.17586/2220-8054-2016-7-3-513-517

\begin{abstract}
$\mathrm{Ru}$ metal doped $\mathrm{TiO}_{2}$ nanoparticles were synthesized using a sol gel method with and without ionic liquid. Ru metal is well dispersed while utilizing ionic liquid as reaction medium for catalyst synthesis with respect to $\mathrm{Ru}^{-\mathrm{TiO}_{2}}$ catalyst. $\mathrm{A}$ TEM image for Ru-TiO $\mathrm{T}_{2}-\mathrm{IL}$ catalyst reveals, stable, well dispersed and agglomeration free $\mathrm{Ru}$ metal doped $\mathrm{TiO}_{2}$ nanoparticles. $\mathrm{CO}_{2}$ Hydrogenation reaction on task specific ionic liquid medium, offered the formic acid in high TON/TOF value with added advantage of 5 times catalyst recycling.
\end{abstract}

Keywords: ruthenium metal, titanium dioxide, nanoparticles, hydrogenation, carbon sequestration, formic acid.

Received: 2 February 2016

Revised: 15 April 2016

\section{Introduction}

Various physiochemical methods have been reported for the fixation of $\mathrm{CO}_{2}$ gas, such as carbonates, geological or ocean storage or afforestation [1-4]. However, these approaches have severe drawbacks in terms of economic factors, safety, efficiency, and reliability of their immediate application. It is also known that functionalized ionic liquid mediated $\mathrm{Ru}$ (II) compounds can promote the partial hydrogenation of $\mathrm{CO}_{2}$ to formic acid where the ionic liquid not only captures the formed formic acid but also shifts the equilibrium of the hydrogenation reaction. The pre-organized structure of imidazolium based ionic liquids (ILs) provides structural directionality though their hydrogen bonding, as opposed to classical salts in which the aggregates display charge-ordering structures [4]. The structural organization of ILs provides a special "entropic drivers" for natural, precise, and prolonged assembling of nanoscale assemblies [5,6]. We successfully applied imidazolium ionic liquids as a template, additive, and solvent for the synthesis of an excess of transition-metal nanoparticles [7]. The catalytic properties (activity and selectivity) of these soluble metal nanoparticles direct that they possess a pronounced surface like (multi-site) rather than singlesite-like catalytic properties [8-10]. The main goal of this proposed work is to develop supported functionalized ionic liquid ruthenium nanoparticles [11] in $\mathrm{TiO}_{2}$ (nanoparticles and nanotubes) for the hydrogenation of $\mathrm{CO}_{2}$.

\section{Experimental}

Reagent Plus ${ }^{\circledR}$ grade ruthenium (III) chloride hydrate and titanium tetraisopropoxide were purchased from Aldrich. Other ReagentPlus ${ }^{\circledR}$ and extra pure grade chemicals were purchased from Spectrochem. Nuclear Magnetic Resonance (NMR) spectra were recorded on a standard Bruker 300WB spectrometer with an Avance console at 400 and $100 \mathrm{MHz}$ for ${ }^{1} \mathrm{H}$ NMR. All the hydrogenation reactions were carried out in a $100 \mathrm{~mL}$ stainless steel autoclave (Amar Equipment, India). The catalyst material was characterized by TEM (Hitachi S-3700N) and Energy-dispersive X-ray spectroscopy (EDX) (Perkin Elmer, PHI 1600 spectrometer). FTIR data for all the samples were studied with Bruker Tensor-27. 1-Butyl-3-methylimidazolium Chloride, 1,3-di(NN-dimethylaminoethyl)-2methylimidazolium trifluoromethanesulfonate ([DAMI][TfO]), 1,3-di(NN-dimethylaminoethyl)-2-methylimidazolium bis (trifluoromethylsulfonyl) imide ([DAMI] $\left.\left[\mathrm{NTf}_{2}\right]\right)$ and 1-butyl-3-methylimidazolium chloride ionic liquids were synthesized as per reported procedures [12,13]. FTIR data for all the samples were studied with Bruker Tensor-27. The morphology of catalysts was investigated by transmission electron microscopy (TEM) using a Philips CM12 instrument. XRD was performed on Philips X-Pert diffractometer. The normalized X-ray absorption near stretcher (XANES) spectra was recorded on BL01C1.

\section{Result and discussion}

We synthesized two different ruthenium metaldoped $\mathrm{TiO}_{2}$ nanoparticles with and without ionic liquids, $\mathrm{Ru}-$ $\mathrm{TiO}_{2}-\mathrm{IL}$ and $\mathrm{Ru}-\mathrm{TiO}_{2}$ respectively, using the sol-gel method and followed by calcination at $250{ }^{\circ} \mathrm{C}$ for 5 hours. The XRD pattern of $\mathrm{TiO}_{2}$ was compared with that of $\mathrm{Ru}-\mathrm{TiO}_{2}-\mathrm{IL}$ and $\mathrm{Ru}-\mathrm{TiO}_{2}$ (Fig. 1) [14] from the wide angle XRD pattern The titania samples were found only in anatase phase with characteristic diffraction peaks of 2 degree values near $42-44^{\circ}$, being assigned to metallic ruthenium (PDF No. 06-0633) observed for the $\mathrm{Ru}-\mathrm{TiO}_{2}$ 
catalyst. However, there were no characteristic peaks of $\mathrm{Ru}^{\circ}$ observed for the $\mathrm{Ru}-\mathrm{TiO}_{2}-\mathrm{IL}$ catalyst, indicating a high dispersion of $\mathrm{Ru}$ on the $\mathrm{TiO}_{2}$ support.

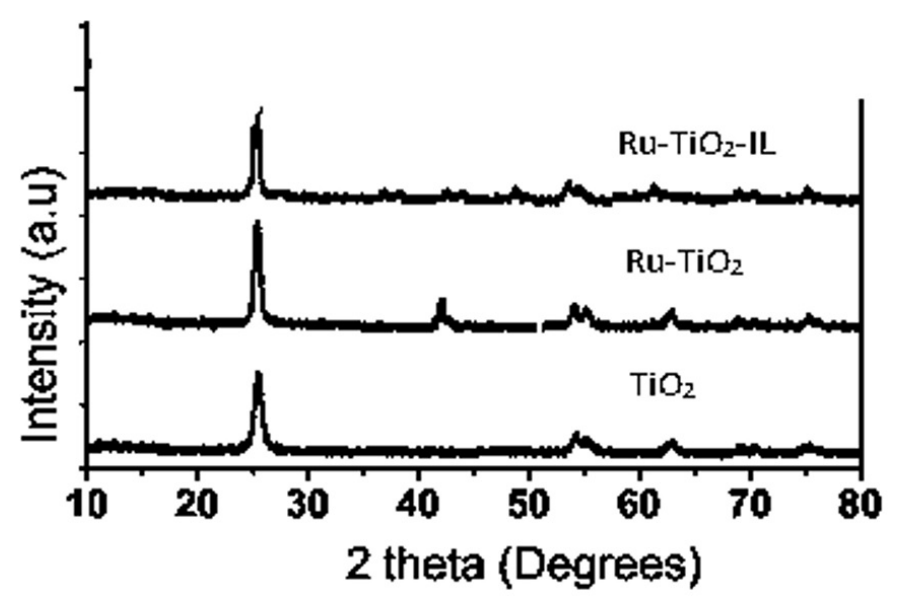

FIG. 1. XRD data for ruthenium metal doped titanium dioxide nanoparticles

The FTIR analysis of $\mathrm{TiO}_{2}$ with respect to $\mathrm{Ru}-\mathrm{TiO}_{2}-\mathrm{IL}$ and $\mathrm{Ru}-\mathrm{TiO}_{2}$ catalysts was carried out from 400 $4000 \mathrm{~cm}^{-1}$ (Fig. 2). In Ru loaded $\mathrm{TiO}_{2}$, clear bands for the $\mathrm{O}-\mathrm{Ti}-\mathrm{O}$ bonding were found near 445 and $708 \mathrm{~cm}^{-1}$. The representing band for $\delta-\mathrm{H}_{2} \mathrm{O}$ bending appeared near to $1605 \mathrm{~cm}^{-1}$. A broad absorption band showing the-O and $\mathrm{O}-\mathrm{Ti}-\mathrm{O}$ flexion vibration band found between $400 \mathrm{~cm}^{-1}$ and $800 \mathrm{~cm}^{-1}$.

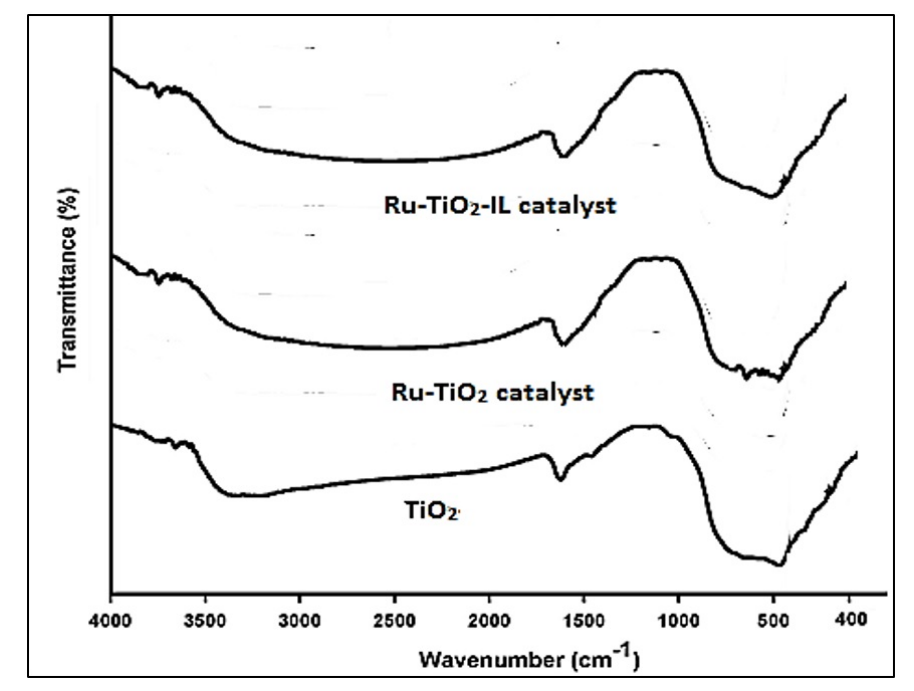

FIG. 2. Infrared data for $\mathrm{Ru}-\mathrm{TiO}_{2}$ nanoparticles

TEM micrographs of $\mathrm{TiO}_{2}, \mathrm{Ru}-\mathrm{TiO}_{2}-\mathrm{IL}$ and $\mathrm{Ru}-\mathrm{TiO}_{2}$ are shown in Fig. 3. Electron microscopy reveals the morphology of the $\mathrm{TiO}_{2}, \mathrm{Ru}-\mathrm{TiO}_{2}-\mathrm{IL}$ and $\mathrm{Ru}-\mathrm{TiO}_{2}$. It was clearly observed that for $\mathrm{Ru}-\mathrm{TiO}_{2}$ catalyst, many severely strained ruthenium nanoparticles larger than $25 \pm 5 \mathrm{~nm}$ were found on the surface of $\mathrm{TiO}_{2}$ while in $\mathrm{Ru}-\mathrm{TiO}_{2}-\mathrm{IL}$ catalysts, ultrafine Ru nanoparticles with uniform particle size were dispersed on the surface of $\mathrm{TiO}_{2}$. It is worth noting here that no particles larger than $20 \mathrm{~nm}$, were observed despite our careful attention. More intuitively, the average particle size for the $\mathrm{Ru}-\mathrm{TiO}_{2}$ catalyst was found to be $25 \pm 5 \mathrm{~nm}$. However, it was only $15 \pm 5 \mathrm{~nm}$ with narrower particle size spreading for the $\mathrm{Ru}-\mathrm{TiO}_{2}-\mathrm{IL}$ catalyst. These observations indicated that the reaction medium type could remarkably affect the dispersion of $\mathrm{Ru}$ on the $\mathrm{TiO}_{2}$ surface and the ionic liquid was a more efficient reaction medium than conventional solvents to stabilize the smaller nano-sized particles of Ru.

Theoretical (cation exchange capacity) and an experimental (ICP-AES) method was used to calculate the amount of $\mathrm{Ru}$ species in $\mathrm{TiO}_{2}$. Both theoretical and experimental values were found to be in good agreement, and $2.5 \mathrm{wt} \% \mathrm{Ru}$ was found in the $\mathrm{Ru}-\mathrm{TiO}_{2}-\mathrm{IL}$ catalyst while in $\mathrm{Ru}-\mathrm{TiO}_{2}$ catalyst, there was $2.1 \mathrm{wt} \% \mathrm{Ru}$ metal. 


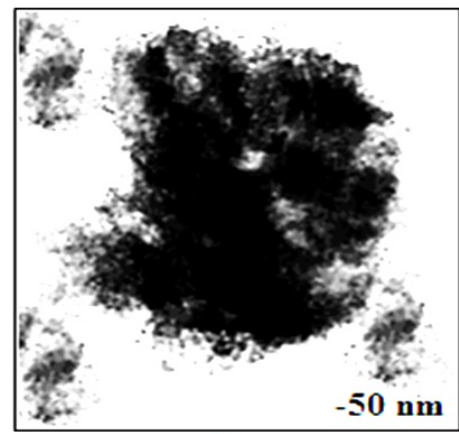

a

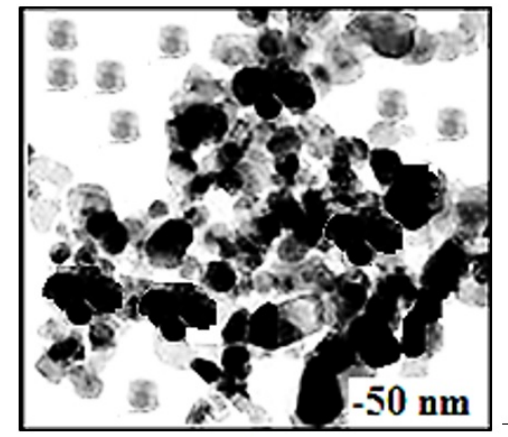

b

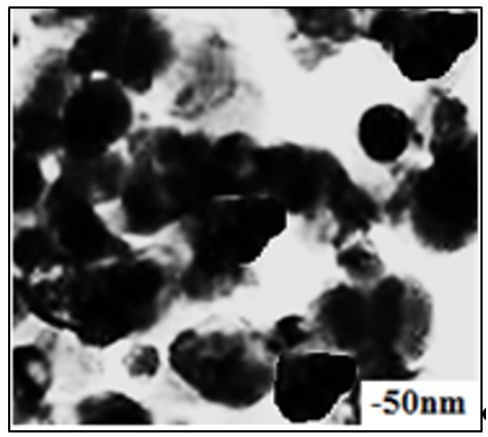

c

FIG. 3. TEM data for Ruthenium Metal Doped Titanium Dioxide Nanoparticles. (a) $\mathrm{Ru}-\mathrm{TiO}_{2}$ catalyst,(b) $\mathrm{Ru}-\mathrm{TiO}_{2}$-IL catalyst (Before catalysis), (c) $\mathrm{Ru}-\mathrm{TiO}_{2}$-IL catalyst (After catalysis)

This protocol also minimizes the loss of Ru nanoparticles during the process. Hydrogenation of $\mathrm{CO}_{2}$ was carried out using $\mathrm{H}_{2}$ gas in the presence of both the catalysts (without any pretreatment) with functionalized ionic liquids separately at $80{ }^{\circ} \mathrm{C}$ under high pressure. After the reaction, formic acid was isolated from the reaction mass followed by the nitrogen flow at $125-130{ }^{\circ} \mathrm{C}$. The results obtained while optimizing the reaction conditions with respect to TON/TOF values for formic acid were summarized in Table 1, entry $1-17$. Acid-base titration using phenolphthalein indicator and ${ }^{1} \mathrm{H}$ NMR analysis was used to calculate the quantity of formic acid formed [12,13].

Initially, both catalysts were tested under the same reaction conditions for $\mathrm{CO}_{2}$ hydrogenation and high TON/TOF values were obtained with $[\mathrm{DAMI}]\left[\mathrm{NTf}_{2}\right]$ immobilized $\mathrm{Ru}-\mathrm{TiO}_{2}-\mathrm{IL}$ (Table1, Entry 1 \& 2). All the other important reaction parameters and technical variables were investigated using [DAMI] $\left.\mathrm{NTf}_{2}\right]$ immobilized $\mathrm{Ru}-\mathrm{TiO}_{2}$-IL (Table 1, Entry 3 - 17). We obtained good TON/TOF value at $100{ }^{\circ} \mathrm{C}$ when, the total $\mathrm{H}_{2} / \mathrm{CO}_{2}$ gas pressure was $40 \mathrm{MPa}$ (Table 1, Entry 3). The effect of water was also studied on the reaction kinetics of $\mathrm{CO}_{2}$ hydrogenation reaction only, with $2 \mathrm{ml}$ of water with a high TON/TOF value (Table 1, entry 12). $\mathrm{CO}_{2}$ may react with water and an amine group of ionic liquid to give off bicarbonates which may act as a perfect substrate for the hydrogenation reaction. $\mathrm{RuCl}_{3}$ was also evaluated for the hydrogenation reaction, but formic acid was obtained with a low TON/TOF value compared to [DAMI] [NTf ${ }_{2}$ immobilized Ru-TiO 2 -IL (Table 1), Entry 17). After the reaction, formic acid was isolated with the aid of $\mathrm{N}_{2}$ gas and the [DAMI] [NTf $\mathrm{N}_{2}$ ionic liquid immobilized $\mathrm{Ru}-\mathrm{TiO}_{2}-\mathrm{IL}$ went for a recycling test after washing with diethyl ether. [DAMI] $\left[\mathrm{NTf}_{2}\right.$ ] ionic liquid immobilized $\mathrm{Ru}-\mathrm{TiO}_{2}-\mathrm{IL}$ were recycled up to 5 times with slight loss of their catalytic action mainly because of agglomeration of Ru NPs which was also confirmed by TEM analysis of the Ru NPs (Fig. 4).

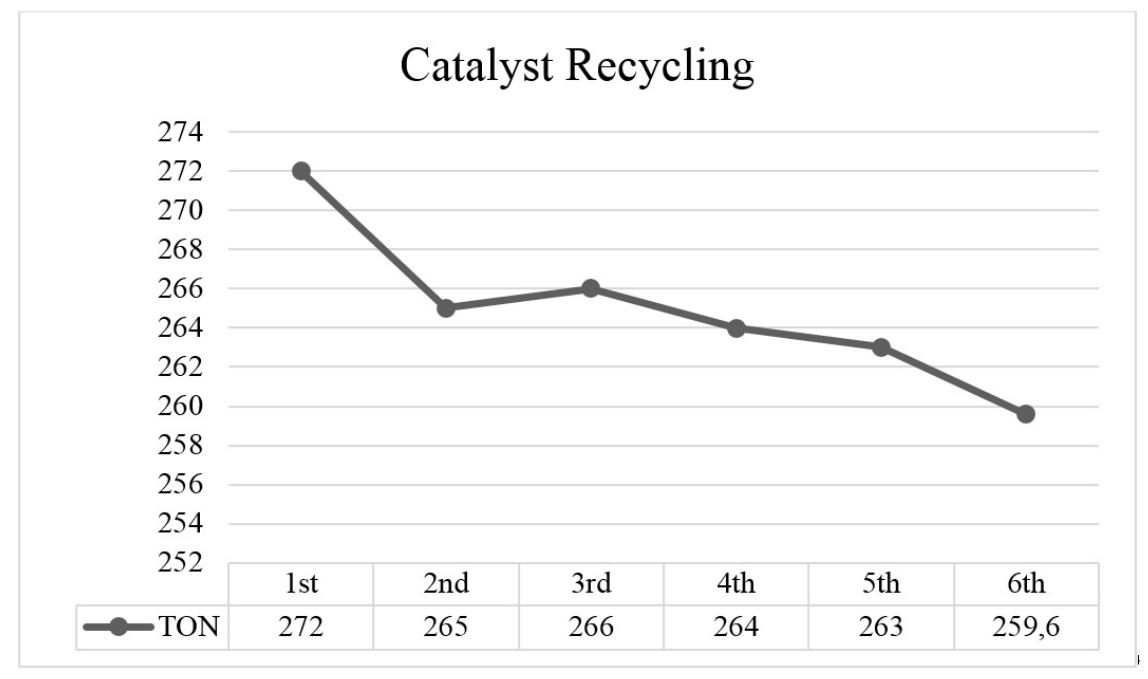

FIG. 4. Catalyst recycling experiment 
TABLE 1. Hydrogenation of $\mathrm{CO}_{2}$ to Formic acid using ionic liquid immobilized $\mathrm{TiO}_{2}$ dropped $\mathrm{Ru}$ metal ${ }^{1}$

\begin{tabular}{|c|c|c|c|c|c|}
\hline Entry & Catalytic system & $\begin{array}{c}\mathrm{P}\left(\mathrm{H}_{2}\right) \mathrm{P}_{\text {total }} \\
(\mathrm{MPa})^{2}\end{array}$ & $\begin{array}{l}\text { Tempera- } \\
\text { ture }\left({ }^{\circ} \mathrm{C}\right)\end{array}$ & $\begin{array}{l}\text { Time } \\
\text { (h) }\end{array}$ & $\mathrm{TON}^{3}$ \\
\hline 1. & $\mathrm{Ru}-\mathrm{TiO}_{2}-\mathrm{IL} /[\mathrm{DAMI}][\mathrm{TfO}]$ & $20(40)$ & 80 & 1 & 252 \\
\hline 2. & $\mathrm{Ru}-\mathrm{TiO}_{2} /[\mathrm{DAMI}][\mathrm{TfO}]$ & $20(40)$ & 80 & 1 & 222 \\
\hline 3. & $\mathrm{Ru}-\mathrm{TiO}_{2}-\mathrm{IL} /[\mathrm{DAMI}]\left[\mathrm{NTf}_{2}\right]$ & $20(40)$ & 80 & 1 & 246 \\
\hline 4. & $\mathrm{Ru}-\mathrm{TiO}_{2}-\mathrm{IL} /[\mathrm{DAMI}][\mathrm{TfO}]$ & $20(40)$ & 100 & 1 & 253 \\
\hline 5. & $\mathrm{Ru}-\mathrm{TiO}_{2}-\mathrm{IL} /[\mathrm{DAMI}][\mathrm{TfO}]$ & $20(40)$ & 120 & 1 & 253 \\
\hline 6. & $\mathrm{Ru}-\mathrm{TiO}_{2}-\mathrm{IL} /[\mathrm{DAMI}][\mathrm{TfO}]$ & $20(40)$ & 50 & 1 & 195 \\
\hline 7. & $\mathrm{Ru}-\mathrm{TiO}_{2}-\mathrm{IL} /[\mathrm{DAMI}][\mathrm{TfO}]$ & $20(40)$ & 100 & 1.5 & 152 \\
\hline 8. & $\mathrm{Ru}-\mathrm{TiO}_{2}-\mathrm{IL} /[\mathrm{DAMI}][\mathrm{TfO}]$ & $20(40)$ & 100 & 0.3 & 85 \\
\hline 9. & $\mathrm{Ru}-\mathrm{TiO}_{2}-\mathrm{IL} /[\mathrm{DAMI}][\mathrm{TfO}]$ & $10(20)$ & 100 & 1 & 195 \\
\hline 10. & $\mathrm{Ru}-\mathrm{TiO}_{2}-\mathrm{IL} /[\mathrm{DAMI}][\mathrm{TfO}]$ & $30(60)$ & 100 & 1 & 252 \\
\hline 11. & $\mathrm{Ru}-\mathrm{TiO}_{2}-\mathrm{IL} /[\mathrm{DAMI}][\mathrm{TfO}]+\mathrm{H}_{2} \mathrm{O}(1 \mathrm{~mL})$ & $20(40)$ & 100 & 1 & 258 \\
\hline 12. & $\mathrm{Ru}-\mathrm{TiO}_{2}-\mathrm{IL} /[\mathrm{DAMI}][\mathrm{TfO}]+\mathrm{H}_{2} \mathrm{O}(2 \mathrm{~mL})$ & $20(40)$ & 100 & 1 & 270 \\
\hline 13. & $\mathrm{Ru}-\mathrm{TiO}_{2}-\mathrm{IL} /[\mathrm{DAMI}][\mathrm{TfO}]+\mathrm{H}_{2} \mathrm{O}(3 \mathrm{~mL})$ & $20(40)$ & 100 & 1 & 272 \\
\hline 14. & $\mathrm{Ru}-\mathrm{TiO}_{2}-\mathrm{IL} /[\mathrm{DAMI}][\mathrm{TfO}](0.100 \mathrm{~g})+\mathrm{H}_{2} \mathrm{O}(2 \mathrm{~mL})$ & $20(40)$ & 100 & 1 & 272 \\
\hline 15. & $\mathrm{Ru}-\mathrm{TiO}_{2}-\mathrm{IL} /[\mathrm{DAMI}][\mathrm{TfO}](0.500 \mathrm{~g})+\mathrm{H}_{2} \mathrm{O}(2 \mathrm{~mL})$ & $20(40)$ & 100 & 1 & 272 \\
\hline 16. & $\mathrm{Ru}-\mathrm{TiO}_{2}-\mathrm{IL} /[\mathrm{DAMI}]\left[\mathrm{NTf}_{2}\right]+\mathrm{H}_{2} \mathrm{O}(2 \mathrm{~mL})$ & $20(40)$ & 100 & 1 & 260 \\
\hline 17. & $\mathrm{RuCl}_{3}(0.07 \mathrm{~g})^{4}+[\mathrm{DAMI}]\left[\mathrm{NTf}_{2}\right](0.250 \mathrm{~g})$ & $20(40)$ & 100 & 1 & 224 \\
\hline
\end{tabular}

1. Reaction conditions: $0.250 \mathrm{~g}$ catalytic system; 2 . The total pressure of the system is indicated in parentheses;

3. Turn over number $=n$ (formic acid) $n(\mathrm{Ru})^{-1}$ in one reaction cycle; 4 . Turnover frequency $=n$ (formic acid) $n(\mathrm{Ru}){ }^{-1} \mathrm{~h}^{-1} ; 5 . \mathrm{RuCl}_{3} \cdot x \mathrm{H}_{2} \mathrm{O}(50 \% \mathrm{Ru}$ metal $)$.

\section{Conclusion}

Here, we reported the synthesis of air/moisturestable, $\mathrm{TiO}_{2}$ supported $\mathrm{Ru}$ nanoparticles with a narrow particle size distribution. The [DAMI] $\left[\mathrm{NTf}_{2}\right]$ ionic liquid immobilized $\mathrm{Ru}-\mathrm{TiO}_{2}-\mathrm{IL}$ catalyst was found to be highly active in terms of TON/TOF value for the production of formic acid over conventional and $\mathrm{Ru}^{-\mathrm{TiO}_{2}}$ catalyst. Effect of water was also studied during the $\mathrm{CO}_{2}$ hydrogenation reaction. The presence of functionalized ionic liquid as well as water was promising. Five times catalyst recycling, low catalyst loading and selectivity were the major advantages for this proposed protocol.

\section{Acknowledgement}

This work is financially supported by DST Fast Track (SB/FT/CS-124/2012).

\section{References}

[1] Sakakura T., Choi J.C., Yasuda H. Transformation of Carbon Dioxide Chem. Rev., 2007, 107 (6), P. $2365-2387$.

[2] Thampi K.R., Kiwi J., Gratzel M. Methanation and photo-methanation of carbon dioxide at room temperature and atmospheric pressure. Nature, 1987, 327 (6122), P. 506-508.

[3] Zhang Z.F., Xie E., Li W.J., Hu S.Q., Song J.L., Jiang T., Han B.X. Hydrogenation of Carbon Dioxide is Promoted by a Task-Specific Ionic Liquid. Angew. Chem. Int. Edit., 2008, 47 (6), P. 1127-1129.

[4] Dupont J. On the solid, liquid and solution structural organization of imidazolium ionic liquids. J. Braz. Chem. Soc., 2004 , 15 (3), P. 341-350.

[5] Migowski P., Dupont J. Catalytic Applications of Metal Nanoparticles in Imidazolium Ionic Liquids. Chem. Eur. J., 2007, 13 (1), P. 32-39.

[6] Antonietti M., Kuang D.B., Smarsly B., Yong Z. Ionic Liquids for the Convenient Synthesis of Functional Nanoparticles and Other Inorganic Nanostructures. Angew. Chem. Int. Edit., 2004, 43 (38) P. 4988-4992. 
[7] Dupont J., Fonseca G.S., Umpierre A.P. Fichtner P.F.P., Teixeira S.R. Transition-Metal Nanoparticles in Imidazolium Ionic Liquids: Recyclable Catalysts for Biphasic Hydrogenation Reactions. J. Am. Chem. Soc., 2002, 124 (16), P. 4228-4229.

[8] Scheeren C.W., Machado G., Dupont J., Fichtner P.F.P., Texeira S.R. Nanoscale Pt(0) Particles Prepared in Imidazolium Room Temperature Ionic Liquids: Synthesis from an Organometallic Precursor, Characterization, and Catalytic Properties in Hydrogenation Reactions. Inorg. Chem., 2003, 42 (15), P. 4738-4742.

[9] Scheeren C.W., Machado G., Texeira S.R., Morais J., Domingos J.B., Dupont J. Synthesis and Characterization of Pt(0) Nanoparticles in Imidazolium Ionic Liquids. J. Phys. Chem. B, 2006, 110 (26), P. 13011-13020.

[10] Cassol C.C., Umpierre A.P., Machado G., Wolke S.I., Dupont J. The Role of Pd Nanoparticles in Ionic Liquid in the Heck Reaction. J. Am. Chem. Soc., 2005, 127 (10), P. 3298-3299.

[11] Silveira E.T., Umpierre A.P., Rossi L.M., Machado G., Morais J., Soares G.V., Baumvol I.L.R., Teixeira S.R., Fichtner P.F.P., Dupont J. The Partial Hydrogenation of Benzene to Cyclohexene by Nanoscale Ruthenium Catalysts in Imidazolium Ionic Liquids. Chem. Eur. J., 2004, 10 (15) P. 3734-3740.

[12] Srivastava V. In Situ Generation of Ru Nanoparticles to Catalyze $\mathrm{CO}_{2}$ Hydrogenation to Formic Acid. Catalysis letters, 2014,144 (10), P. $1745-1750$.

[13] Srivastava V. Ru-exchanged MMT Clay with Functionalized Ionic Liquid for Selective Hydrogenation of $\mathrm{CO}_{2}$ to Formic acid. Catalysis letters, 2014, 144 (12) P. 2221-2226.

[14] Wang Y., Zhang R., Li J., Li L., Lin S. First-principles study on transition metal-doped anatase TiO 2 . Nanoscale Research Letters, 2014, 9 (1), P. 46.

[15] Bagheri S., Chekin F., Hamid S.B.A. Cobalt Doped Titanium Dioxide Nanoparticles: Synthesis, Characterization and Electrocatalytic Study. J. Chin. Chem. Soc., 2014, 61 (6), P. 702-706. 